Supporting Information to

\title{
Depolymerization-Induced Electrochemiluminescence of Insoluble Porphyrin in
}

\section{Aqueous Phase}

Yanxia Wu,${ }^{\dagger \S}$ Zhengang Han, ${ }^{\dagger \S}$ Liping Wei,${ }^{\dagger}$ Heshui Sun,,${ }^{\dagger}$ Tieying Wang,${ }^{\dagger}$ Jing Chen,${ }^{\dagger}$ Ruizhong

$$
\text { Zhang, }{ }^{* \ddagger} \text { and Xiaoquan } \mathrm{Lu}^{*+\ddagger}
$$

${ }^{\dagger}$ Key Laboratory of Bioelectrochemistry and Environmental Analysis of Gansu Province, College of Chemistry and Chemical Engineering, Northwest Normal University, Lanzhou 730070, People's Republic of China

*Tianjin Key Laboratory of Molecular Photoelectronic Sciences, Department of Chemistry, Tianjin University, Tianjin 300072, People's Republic of China

$\S$ These authors contributed equally.

*Corresponding authors: zhangrz2019@tju.edu.cn; luxq@nwnu.edu.cn, luxq@tju.edu.cn.

\section{Table of Contents}

1. Synthesis and characterization of 5,10,15,20-tetrakis(4-Hydroxyl)phenyl porphyrin (THPP)

2. Synthesis of supramolecular self-assembly of THPP and $\beta$-CD (THPP@ $\beta$-CD)

3. ECL efficiency calculation of THPP@ $\beta-C D$

4. Supplementary schematic diagrams and figures

5. References 


\section{Synthesis and characterization of $\mathbf{5 , 1 0 , 1 5 , 2 0 - t e t r a k i s ( 4 - H y d r o x y l ) p h e n y l ~ p o r p h y r i n ~}$ (THPP)}

Specifically, $1.5275 \mathrm{~g}$ p-hydroxybenzaldehyde was first dissolved in $125 \mathrm{~mL}$ dried propionic acid in $250 \mathrm{~mL}$ three-necked flask under rapid stirring and $\mathrm{N}_{2}$ flow protection. After the mixture was heated up to reflux temperature $\left(145^{\circ} \mathrm{C}\right) 15 \mathrm{~mL}$ propionic acid solution of polypyrrole $(870 \mu \mathrm{L}$, fresh evaporated) was added and refluxed for another $2 \mathrm{~h}$. The propionic acid was then removed by distilling and cooled down to room temperature. The residue was further mixed with $100 \mathrm{~mL}$ ethanol and stayed overnight. After that, by using crystallization,filteration andwashing with trichloromethane until seeing the clarifiedfiltrate, and purple solid product was obtained. Finally, the dried crude product was dissolved in acetone to make a saturated solution, 200-300 mesh silica gel and acetone was used as the stationary phase and themobile phase, respectively, for column chromatography to collect a second purple band, which was further recrystallized from acetonediethyl ether, filtered and dried to get a purple final desired product. ${ }^{1} \mathrm{H}$ NMR (DMSO- $d 6$ ) : $\delta-2.78$ (s, 2H, NH), $7.32 \sim 7.34$ (d, 8H, m- $\left.\mathrm{C}_{6} \mathrm{H}_{4} \mathrm{OH}\right), 8.11 \sim 8.13\left(\mathrm{~d}, 8 \mathrm{H}, \mathrm{C}_{6} \mathrm{H}_{4} \mathrm{OH}\right), 8.99$ (s, 8H, $\mathrm{CH}_{2}$ ), $10.10(\mathrm{~s}, 4 \mathrm{H}, \mathrm{OH})$.

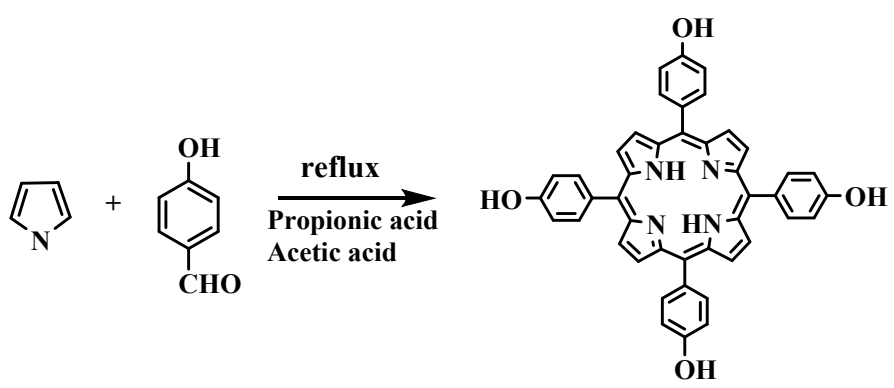

Scheme S1. Synthesis of 5,10,15,20-tetrakis(4-Hydroxyl)phenyl porphyrin (THPP).

\section{Synthesis of supramolecular self-assembly of THPP and $\beta$-CD (THPP@ß-CD)}

Typically, $500 \mu \mathrm{L} 1 \mathrm{mM} \mathrm{N}$, N-dimethylformamide (DMF) solution of THPP was firstly prepared, and $500 \mu \mathrm{L} 0.1 \mathrm{M}$ PBS ( $\mathrm{pH}=7.0$ ) was then added for protonation. After that, the above solution was transferred into a volumetric flask and fixed the total volume to be $5 \mathrm{~mL}$ by adding the ultrapure water. The self-assembly of THPP and $\beta$-CD (THPP@ $\beta-C D)$ was further obtained by mixing $\beta$-CD aqueous solution $(0.33 \mathrm{mM}, 150 \mu \mathrm{L})$ with above protonated THPP solution $(5 \mathrm{~mL})$ under intense agitation for $15 \mathrm{~min}$, the final molar ratio of THPP and $\beta$-CD is 1:1 in this case. To get the optimal DIECL performance, the THPP@ $\beta$-CD self-assembly with different molar ratios 
THPP and $\beta$-CD were also prepared with the same procedure by keeping the THPP constant while adjusting the concentration of $\beta$-CD stock solution. For the universality of this DIECL behavior of porphyrins, meso-tetrasubstituted porphyrins (TCPP, TNPP, TAPP, TPYP, TFPP) and $\beta$-CD selfassemblies were prepared as well using the same procedure by mixing $500 \mu \mathrm{L} 0.1 \mathrm{mM}$ TNPP (TCPP, TAPP, TPYP, TFPP) and $150 \mu \mathrm{L} 0.33 \mathrm{mM} \beta-\mathrm{CD}$.

\section{ECL Efficiency Calculation of THPP@ $\beta-C D$}

The ECL efficiency $(\Phi)$ was calculated according to previous reported method, and $\left[\mathrm{Ru}(\mathrm{bpy})_{3}\right]^{2+}$ was used as a reference. ${ }^{[1,2]}$ The ECL efficiency $\left(\Phi_{\mathrm{x}}\right)$ of was calculated as described in equation S1:

$$
\emptyset_{x}=100 \% \frac{\left[\frac{\left[\int_{a}^{b} \int_{a}^{b} d t\right.}{\int_{a}^{b} d t}\right]_{x}}{\left[\frac{\int_{a}^{b} I d t}{\int_{a}^{b} i d t}\right]_{r}}
$$

where $\Phi$ is the ECL efficiency relative to of $\left[\mathrm{Ru}(\mathrm{bpy})_{3}\right]^{2+}, I$ and $i$ represent the DIECL intensity and the electrochemical current value, respectivley. $r$ is the $\left[\mathrm{Ru}(\mathrm{bpy})_{3}\right]^{2+}$ reference and $x$ is the experimental sample. For the determination of $I$ and charge (integration of $i$ relative to time) to $\left[\mathrm{Ru}(\mathrm{bpy})_{3}\right]^{2+}$, the experiment parameters and procedures were operated according to the reported method. ${ }^{[3]}$ While for $I$ and charge of THPP@ $\beta-\mathrm{CD}$, the procedures were the same as the electroluminescence experimental procedures described above. 


\section{Supplementary Schematic Diagrams and Figures}

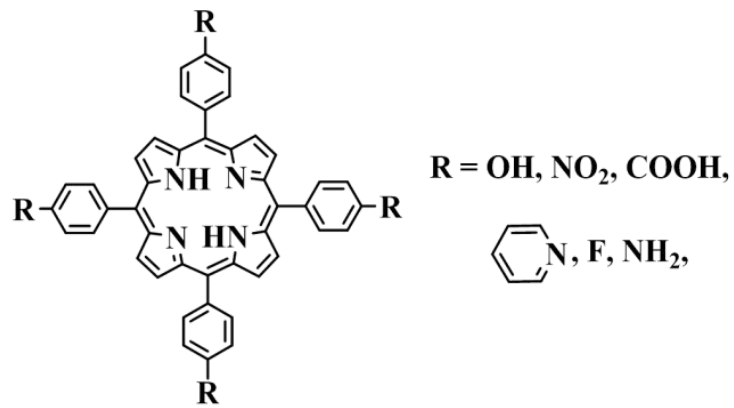

Scheme S2. Chemical structures of different substituted porphyrin, $\mathrm{R}=-\mathrm{OH}$ (THPP), $-\mathrm{NO}_{2}$ (TNPP), -COOH (TCPP), -pyridyl (TPYP), -F (TFPP), - $\mathrm{NH}_{2}$ (TAPP).

b
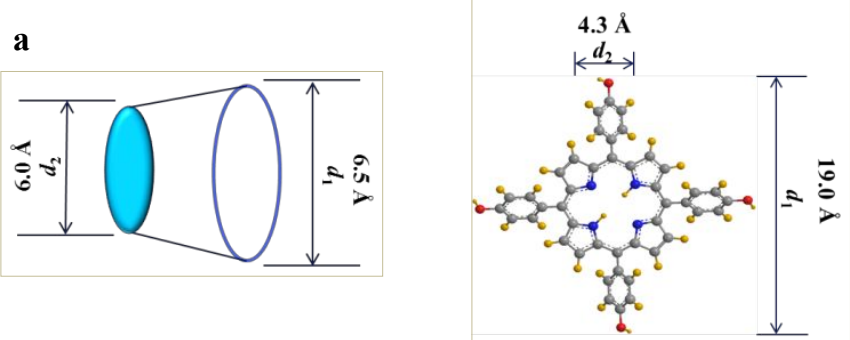

Scheme S3. The opening diameter of (a) $\beta-\mathrm{CD}$ and (b) the size of THPP. 


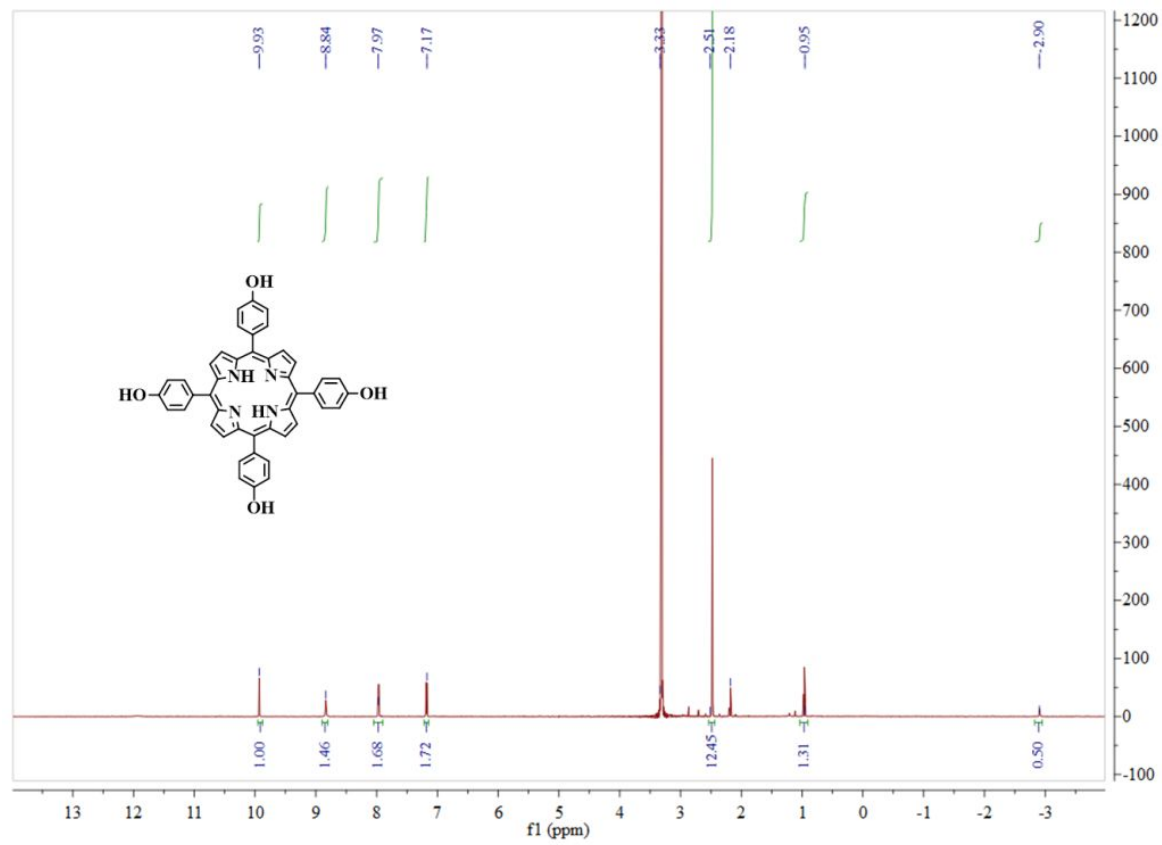

Figure S1. ${ }^{1} \mathrm{H}$ NMR of THPP.

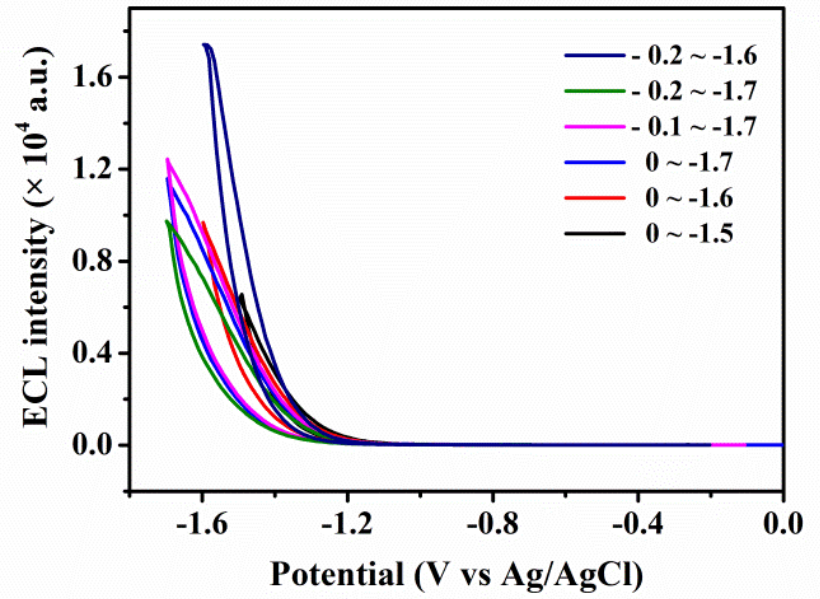

Figure S2. The DIECL intensity-potential curves of $10 \mu \mathrm{M}$ THPP@ $\beta-\mathrm{CD}(\mathrm{n} / \mathrm{n}=1: 1)$ in the presence of $0.1 \mathrm{M} \mathrm{K}_{2} \mathrm{~S}_{2} \mathrm{O}_{8}$ at different potential windows. The supporting electrolyte is $0.1 \mathrm{M}$ PBS ( $\left.\mathrm{pH}=7.0\right)$ containing $0.1 \mathrm{M} \mathrm{KCl}$. 


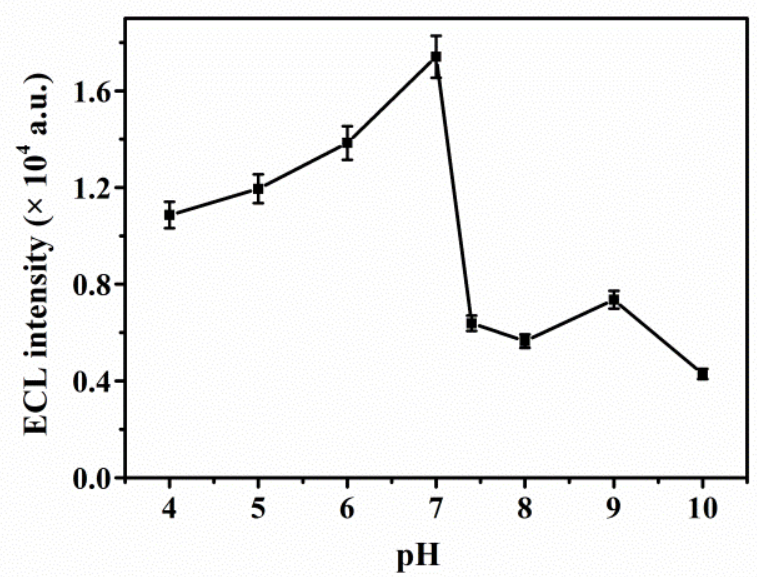

Figure S3. The DIECL intensity of THPP@ $\beta$-CD $(\mathrm{n} / \mathrm{n}=1: 1) / \mathrm{K}_{2} \mathrm{~S}_{2} \mathrm{O}_{8}$ system at various solution $\mathrm{pH}$ values (4 10), where the concentrations of THPP@ $\beta$-CD (n/n=1:1) and $\mathrm{K}_{2} \mathrm{~S}_{2} \mathrm{O}_{8}$ are $10 \mu \mathrm{M}$ and 0.1 $\mathrm{M}$, respectively. The scan rate was $0.1 \mathrm{~V} \mathrm{~s}^{-1}$ and potential window set between $-1.6 \mathrm{~V}$ and $-0.2 \mathrm{~V}$.

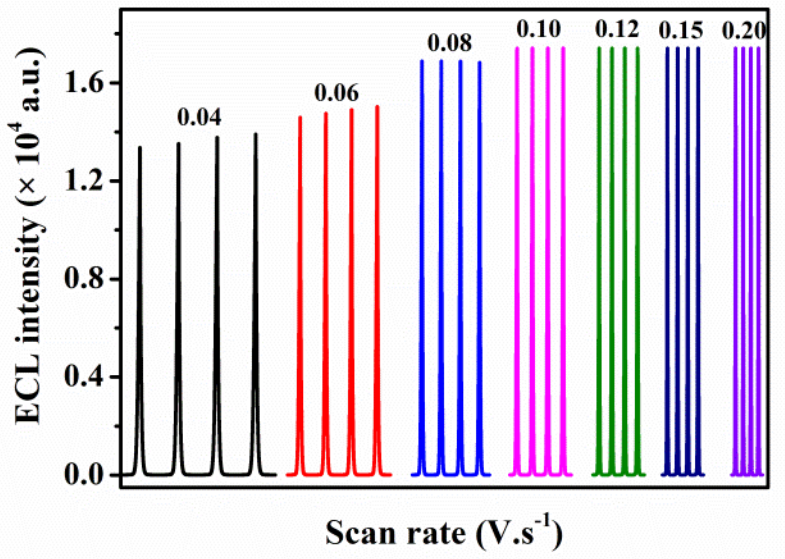

Figure S4. The DIECL intensity of THPP@ $\beta-\mathrm{CD}(\mathrm{n} / \mathrm{n}=1: 1) / \mathrm{K}_{2} \mathrm{~S}_{2} \mathrm{O}_{8}$ system under different scan rates $\left(0.04 \sim 0.2 \mathrm{~V} \mathrm{~s}^{-1}\right)$, where the concentrations of THPP@ $\beta-\mathrm{CD}(\mathrm{n} / \mathrm{n}=1: 1)$ and $\mathrm{K}_{2} \mathrm{~S}_{2} \mathrm{O}_{8}$ are $10 \mu \mathrm{M}$ and $0.1 \mathrm{M}$, respectively. The supporting electrolyte is $0.1 \mathrm{M} \mathrm{PBS}(\mathrm{pH}=7.0)$ containing $0.1 \mathrm{M} \mathrm{KCl}$. 


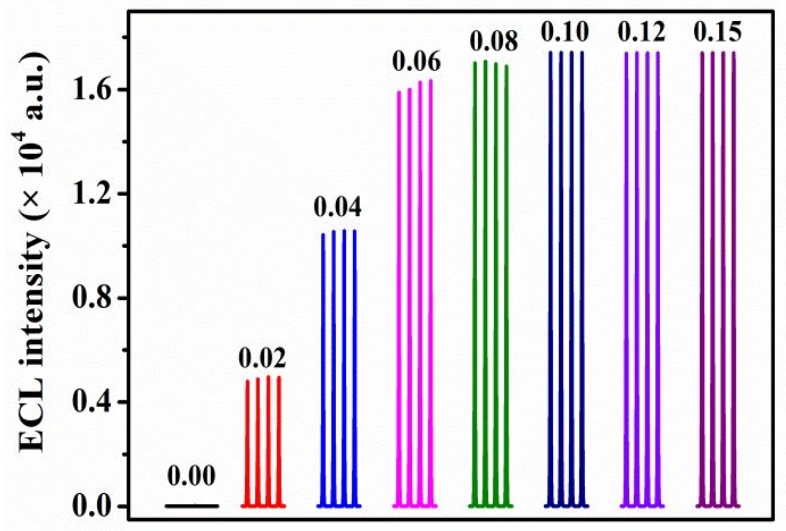

Concentration (M)

Figure S5. The DIECL intensity of $10 \mu \mathrm{M}$ THPP@ $\beta-\mathrm{CD}(\mathrm{n} / \mathrm{n}=1: 1)$ with different dosages of $\mathrm{K}_{2} \mathrm{~S}_{2} \mathrm{O}_{8}(0 \sim 0.15 \mathrm{M})$. The supporting electrolyte is $0.1 \mathrm{M} \mathrm{PBS}(\mathrm{pH}=7.0)$ containing $0.1 \mathrm{M} \mathrm{KCl}$, the scan rate is $0.1 \mathrm{~V} \mathrm{~s}^{-1}$.
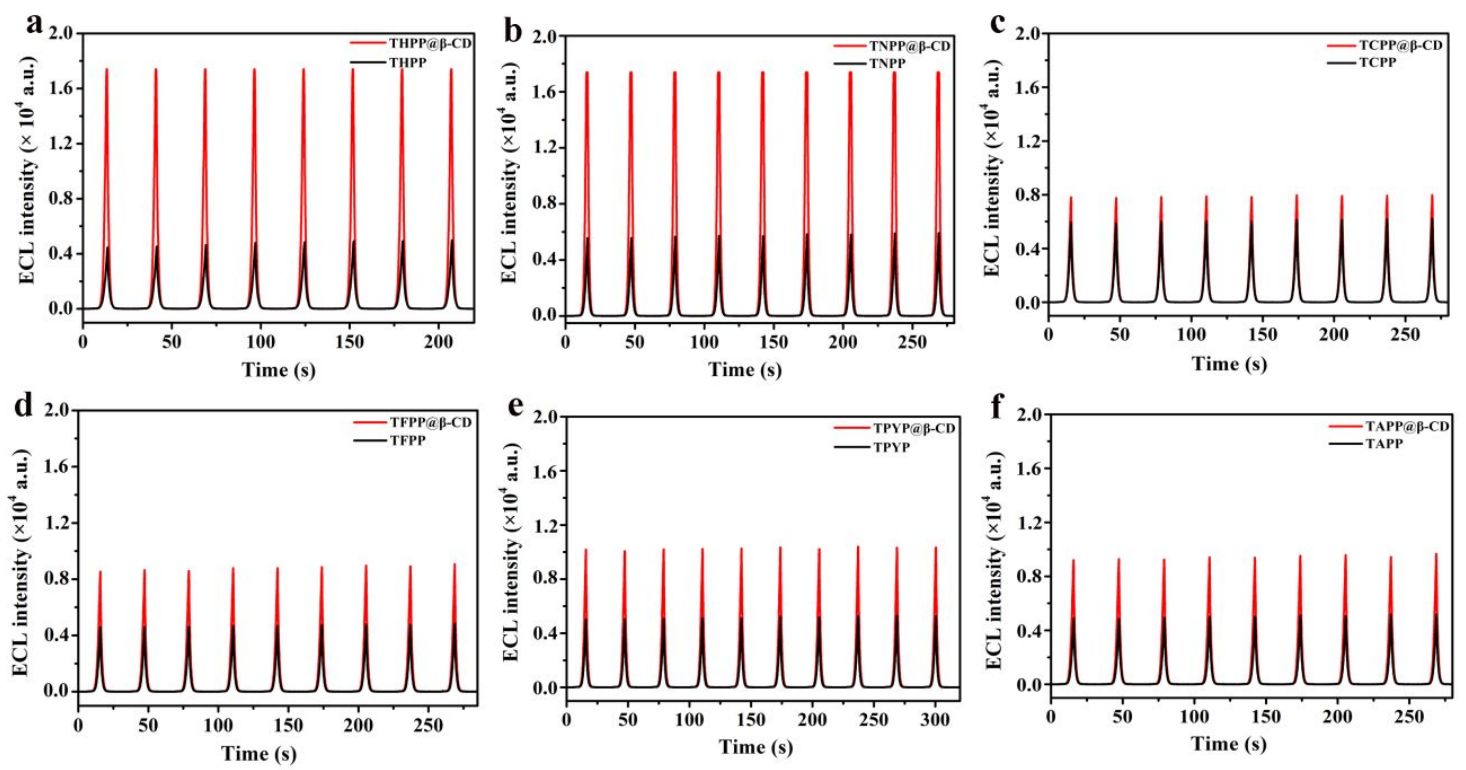

Figure S6. The DIECL intensity-time curves of $10 \mu \mathrm{M}$ different porphyrins (black line) and porphyrin@ $\beta-\mathrm{CD}(\mathrm{n} / \mathrm{n}=1: 1)$ self-assembling systems (red line) in the presence of $0.1 \mathrm{M} \mathrm{K}_{2} \mathrm{~S}_{2} \mathrm{O}_{8}$ : (a) $\operatorname{THPP}(\mathrm{R}=\mathrm{OH}),(\mathrm{b}) \operatorname{TNPP}\left(\mathrm{R}=\mathrm{NO}_{2}\right),(\mathrm{c}) \operatorname{TCPP}(\mathrm{R}=\mathrm{COOH}),(\mathrm{d}) \operatorname{TFPP}(\mathrm{R}=\mathrm{F}),(\mathrm{e}) \operatorname{TPYP}\left(\mathrm{R}=\mathbb{C}^{\mathrm{v}}\right)$ and (f) TAPP $\left(\mathrm{R}=\mathrm{NH}_{2}\right)$. The supporting electrolyte is $0.1 \mathrm{M}$ PBS $(\mathrm{pH}=7.0)$ containing $0.1 \mathrm{M} \mathrm{KCl}$, the scan rate is $0.1 \mathrm{~V} \mathrm{~s}^{-1}$, and the potential window is set between -1.6 and $-0.2 \mathrm{~V}$. 


\section{References}

[1] Peng, H.; Jian, M.; Deng, H.; Wang, W. ; Huang, Z.; Huang, K.; Liu, A.; Chen, W. ACS Appl. Mater. Inter. 2017, 9, 14929-14934.

[2] Wallace, W. L.; Bard, A. J. J. Phys. Chem. 1979, 83, 1350-1357.

[3] Xie, J.; Zheng, Y.; Ying, J. Y. J. Am. Chem. Soc. 2009, 131, 888-889. 